\title{
PENDIDIKAN KESEHATAN PERAWATAN LUKA PERINEUM DAN PEMBERIAN PAKET PERAWATAN LUKA PERINEUM PADA IBU NIFAS DI WILAYAH KERJA PUSKESMAS PRINGSEWU LAMPUNG
}

\author{
Yossy Wijayanti ${ }^{1}$, Diny Vellyana ${ }^{2}$ \\ ${ }^{1}$ Fakultas Kesehatan Universitas Muhammadiyah Pringsewu Lampung \\ ${ }^{2}$ Fakultas Kesehatan Universitas Muhammadiyah Pringsewu Lampung \\ Email : yossywijayanti@umpri.ac.id
}

\begin{abstract}
Abstrack : Pendidikan Kesehatan Perawatan Luka Perineum Dan Pemberian Paket Perawatan Luka Perineum Pada Ibu Nifas Di Wilayah Kerja Puskesmas Pringsewu Lampung. Di Indonesia luka perineum dialami oleh 75\% ibu melahirkan pervaginam. Pada tahun 2013 menemukan bahwa dari total 1951 kelahiran spontan pervaginam, 57\% ibu mendapat jahitan perineum (28\% karena episiotomi dan $29 \%$ karena robekan spontan) (Depkes RI, 2013). Pada persalinan akan terjadi perlukaan pada perineum baik itu karena robekan spontan maupun episiotomi. Penatalaksanaan yang tidak tepat dapat menyebabkan infeksi. Proses penyembuhan luka perineum yang normal adalah 6 sampai 7 hari post partum (Hartiningtyaswati, 2009). Faktor-faktor yang mempengaruhi penyembuhan luka perineum antara lain adalah ibu tidak mengalami kelainan misalnya anemia dan diabetes mellitus, kebutuhan gizi ibu tercukupi dilihat dari IMT ibu, pengetahuan ibu mengenai perawatan luka perineum ibu baik, personal hygiene ibu baik selama masa nifas, ibu melakukan mobilisasi dini 2 jam setelah persalinan pada ibu tidak ada komplikasi (Wiknjosastro, 2013). Oleh sebab itu sebagai salah satu tugas dosen dalam melaksanakan Catur dharma perguruan tinggi, maka kami akan melakukan Pendidikan Kesehatan Perawatan Luka Perineum Dan Pemberian Paket Perawatan Luka Perineum Pada Ibu Nifas Di Wilayah Kerja Puskesmas Pringsewu Lampung. Luaran yang diharapkan adalah proses penyembuhan luka perineum pada ibu nifas dapat berjalan dengan baik sesuai tahapan penyembuhan luka.
\end{abstract}

Kata Kunci : Perawatan luka perineum

\section{Pendahuluan}

Menurut Stefen dalam WHO (2009), terjadi 2,7 juta kasus ruptur perineum pada ibu bersalin. Angka ini diperkirakan mencapai 6,3 juta pada tahun 2050. Di Indonesia luka perineum dialami oleh 75\% ibu melahirkan pervaginam. Pada tahun 2013 menemukan bahwa dari total 1951 kelahiran spontan pervaginam, $57 \%$ ibu mendapat jahitan perineum (28\% karena episiotomi dan 29\% karena robekan spontan) (Depkes RI, 2013)

Pada persalinan akan terjadi perlukaan pada perineum baik itu karena robekan spontan maupun episiotomi. Penatalaksanaan yang tidak tepat dapat menyebabkan infeksi. Infeksi yang terjadi pada luka perineum juga menghambat penyembuhan, sering membersihkan area perineum akan meningkatakan kenyamanan dan mencegah terjadinya infeksi. Sesudah partus terdapat luka-luka di beberapa tempat jalan lahir. Pada hari-hari pertama post partum harus dijaga agar luka ini tidak dimasuki kuman-kuman dari luar (Winkjosartro, 2013).

Proses penyembuhan luka perineum yang normal adalah 6 sampai 7 hari post partum (Hartiningtyaswati, 2009). Faktor-faktor yang mempengaruhi penyembuhan luka perineum antara lain adalah ibu tidak mengalami kelainan misalnya anemia dan diabetes mellitus, kebutuhan gizi ibu tercukupi dilihat dari IMT ibu, pengetahuan ibu mengenai perawatan luka perineum ibu baik, personal hygiene ibu baik selama masa nifas, ibu melakukan mobilisasi dini 2 jam setelah persalinan pada ibu tidak ada komplikasi (Wiknjosastro, 2013). 


\section{BAGIMU NEGERI : JURNAL PENGABDIAN MASYARAKAT \\ P-ISSN : 2548-8651 | E-ISSN : 2548-866X \\ Email : ejournal@umpri.ac.id}

\section{Metode}

Kegiatan ini dilakukan dengan perencanaan yaitu bersama dengan panitia dan pihak Puskesmas melakukan rapat koordinasi dalam waktu pelaksanaan pengabdian masyarakat. Kedua bersama dengan pihak panitia menyiapkan tempat dan melakukaan persamaan persepsi. Ketiga melakukan pelatihan cara memberikan edukasi kepada ibu nifas tentang perawatan luka perineum. Kelima panitia bersama peserta memberikan paket perawatan luka perineum pada ibu nifas. Keenam , pada saat proses perencanaan pelaksanaan jam 08.00 WIB.

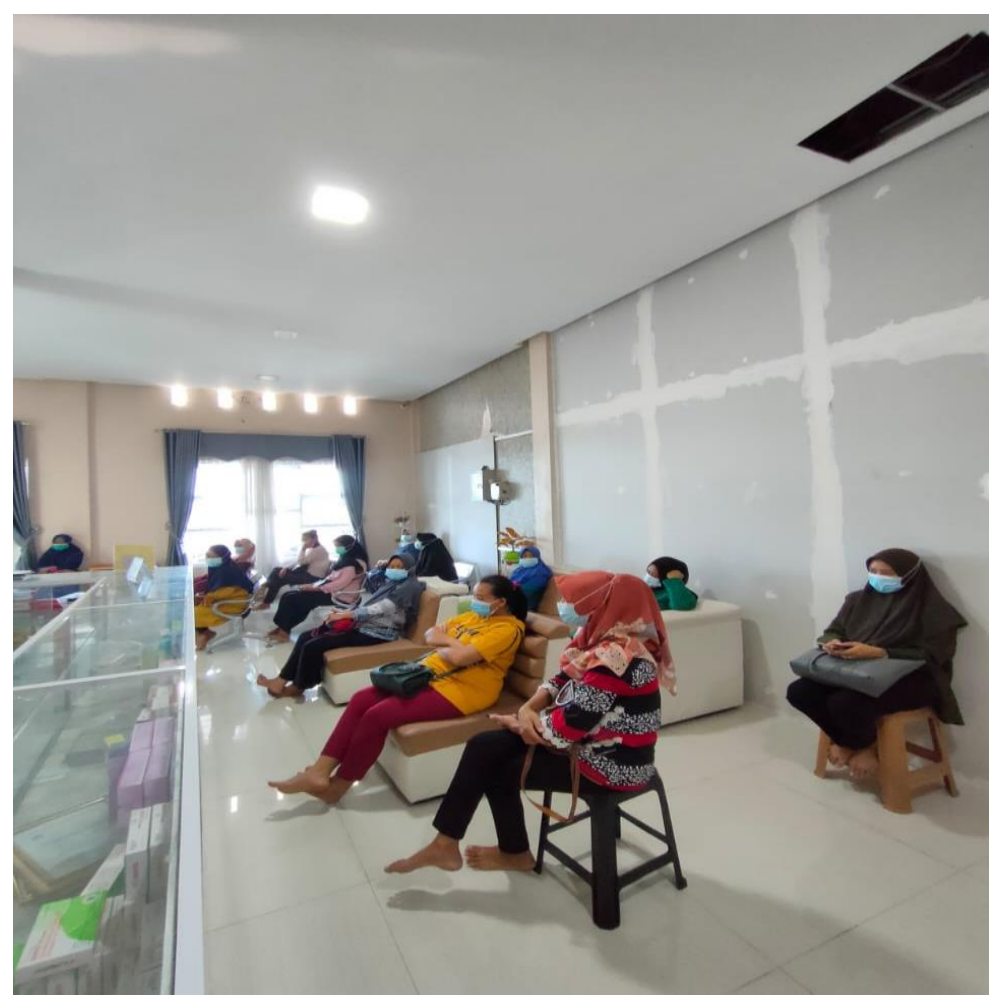

\section{Hasil Dan Pembahasan}

Kegiatan pendidikan kesehatan perawatan luka perineum dan pemberian paket perawatan luka perineum pada ibu nifas di Puskesmas Pringsewu Lampung. Proses pelaksanaan dilakukan pada ibu nifas hari kedua yang melahirkan di wilayah Puskesmas Pringsewu. Pada pengabdian ini mahasiswa lebih terlibat dalam mendapatkan infromasi terkait ibu nifas dan memberikan pelatihan. Mahasiswa dan dosen bekerja sama mengatur jadwal untuk setiap ibu yang melahirkan untuk segera diberikan pendidikan kesehatan perawatan luka perineum dan paket perawatan luka perineum (paket terdiri dari: kassa steril, sabun antiseptik dan pembalut maternity).Proses pelakanaan pendidikan kesehatan dan pemberian paket perawatan ibu nifas dilaksanakan dengan baik. Materi yang disampaikan telah dipahami dengan baik terbukti bahwa dari 35 ibu nifas yang mendapatkan pendidikan kesehatan, penyembuhan luka perineum padah kunjungan hari ke 6 sudah ada 30 orang yang lukanya menutup sempurna. Pada akhir sesi, tim mengucapkan terima kasih kepada perserta yang telah mengikuti pelatihan dengan baik. Lama 


\section{BAGIMU NEGERI : JURNAL PENGABDIAN MASYARAKAT \\ P-ISSN : 2548-8651 | E-ISSN : 2548-866X \\ Email : ejournal@umpri.ac.id}

pendidikan kesehatan luka perineum ini adalah 20-30 menit perorang per sesi pertemuan. Menurut Stefen dalam WHO (2009), terjadi 2,7 juta kasus ruptur perineum pada ibu bersalin. Angka ini diperkirakan mencapai 6,3 juta pada tahun 2050. Di Indonesia luka perineum dialami oleh 75\% ibu melahirkan pervaginam. Pada tahun 2013 menemukan bahwa dari total 1951 kelahiran spontan pervaginam, $57 \%$ ibu mendapat jahitan perineum ( $28 \%$ karena episiotomi dan 29\% karena robekan spontan) (Depkes RI, 2013)

Pada persalinan akan terjadi perlukaan pada perineum baik itu karena robekan spontan maupun episiotomi. Penatalaksanaan yang tidak tepat dapat menyebabkan infeksi. Infeksi yang terjadi pada luka perineum juga menghambat penyembuhan, sering membersihkan area perineum akan meningkatakan kenyamanan dan mencegah terjadinya infeksi. Sesudah partus terdapat luka-luka di beberapa tempat jalan lahir. Pada hari-hari pertama post partum harus dijaga agar luka ini tidak dimasuki kuman-kuman dari luar (Winkjosartro, 2013).

Proses penyembuhan luka perineum yang normal adalah 6 sampai 7 hari post partum (Hartiningtyaswati, 2009). Faktor-faktor yang mempengaruhi penyembuhan luka perineum antara lain adalah ibu tidak mengalami kelainan misalnya anemia dan diabetes mellitus, kebutuhan gizi ibu tercukupi dilihat dari IMT ibu, pengetahuan ibu mengenai perawatan luka perineum ibu baik, personal hygiene ibu baik selama masa nifas, ibu melakukan mobilisasi dini 2 jam setelah persalinan pada ibu tidak ada komplikasi (Wiknjosastro, 2013).

Berdasarkan hasil temuan pada pengabdian ini didapatkan hambatan berupa tim harus memastikan ibu yang melahirkan memang mengalami luka perineum di wilayah Puskesmas Pringsewu. Jumlah ini akan mempengaruhi waktu pengabdian menjadi lebih lama. Berdasarkan hal tersebut kemudian tim melakukan koordinasi untuk melakukan dengan menjemput bola pada ibu bersalin di BPM bidan wilayah kerja Puskesmas Pringsewu.

Selama proses ini tidak ditemui kendala yang berarti pada saat dilakukan pendidikan kesehatan perawatan luka perineum dan pemberian paket perawatan luka perineum. Ibu nifas yang akan diberikan pendidikan kesehatan diminta persetujuan untuk diberikan pendidikan kesehatan perawatan luka perineum yang benar kemudian ibu nifas diminta waktunya selama 20-30 menit untuk mengikuti pendidikan kesehatan. Pada akhir sesi ibu nifas kemudian diberikan kesempatan untuk bertanya.

Hasil pada akhir pengabdian seluruhnya terdapat 35 ibu nifas da nada 34 ibu nifas yang difollow up. Hasil evaluasi secara keseluruhan, sebanyak 30 orang ibu nifas luka perineumnya menutup sempurna.

\section{Simpulan Dan Saran}

Setelah diberikan pendidikan kesehatan dapat disimpulkan bahwa selama proses ini tidak ditemui kendala yang berarti pada saat dilakukan pendidikan kesehatan perawatan luka perineum dan pemberian paket perawatan luka perineum. Ibu nifas yang akan diberikan pendidikan kesehatan diminta persetujuan untuk diberikan pendidikan kesehatan perawatan luka perineum yang benar kemudian ibu nifas diminta waktunya selama 20-30 menit untuk mengikuti pendidikan kesehatan. Pada akhir sesi ibu nifas kemudian diberikan kesempatan untuk bertanya.

Hasil pada akhir pengabdian seluruhnya terdapat 35 ibu nifas da nada 34 ibu nifas yang difollow up. Hasil evaluasi secara keseluruhan, sebanyak 30 orang ibu nifas luka perineumnya menutup sempurna. 


\section{BAGIMU NEGERI : JURNAL PENGABDIAN MASYARAKAT \\ P-ISSN : 2548-8651 | E-ISSN : 2548-866X \\ Email : ejournal@umpri.ac.id}

\section{Daftar Rujukan}

Arikunto ,2006. Prosedur penelitian suatu pedekatan praktek. Jakarta:Rieneka cipta

Asih, Risneni. 2016. Asuhan Kebidnan Nifas Dan Menyusui. Jakarta: CV. Trans Info Media

Coad J. dan Dunstall M. 2007. Anatomi dan Fisiologi Untuk Bidan. In : Pendit B.U. Anatomy and Physiology for Midwifes. EGC : Jakarta. H : 304-312

Depkes, 2013.Profil Kesehatan Indonesia Tahun 2010

Dewi, Sunarsih. 2011. Asuhan Kebidanan Ibu Nifas. Jakarta : Selemba Medika.

Hariningtyaswati H. 2009. Hubungan Perilaku Pantang Makanan Dengan Lama Penyembuhan Luka Perineum Pada Ibu Nifas Di Kecamatan Srengat Kabupaten Blitar. Universitas Sebelas Maret. KTI.

Maryunani A. 2014, Peawatan Luka Seksio Caesarea (SC) dan Luka Kebidanan Terkini (dengan penekanan ' most wound healing'), Jakarta : In Media

Nurdin, Mulyadi. (2009). Perlakuan terhadap Ibu Menurut Adat Aceh. http://mulyadinurdin.wordpress.com/2009/12/30/perlakuan-terhadap-ibumenurut-adat-aceh/

Notoatmodjo, S. 2012. Metodologi penelitian Kesehatan. Jakarta : Rineka Cipta

Notoatmodjo, S.2007. Promosi Kesehatan dan Ilmu Perilaku. Rineka Cipta : Jakarta.

Rukiah, A. Yuliani, L dan Liana, M.(2011). Asuhan Kebidanan III (Nifas). Jakarta:CV.Trans Info Media

Rusjiyanto. 2009. Pengaruh Pemberian Suplemen Seng (Zn) Dan Vitamin C Terhadap Kecepatan Penyembuhan Luka Pasca Bedah Di Rumah Sakit Umum Daerah Kabupaten Sukoharjo. Universitas Sebelas Maret. Tesis

Walyani, Purwoastuti. 2016. Asuhan Kebidanan Masa Nifas Dan Menyusui. Yogyakarta : Pustakabarupress

Winkjosatro H, 2013. Ilmu Kebidanan. Jakarta: P.T Bina Pustaka 